\title{
Kajian Strategi Pembelajaran Jarak Jauh Yang Menunjang Kesehatan Mental Di Sekolah Dasar
}

\author{
Evita Adnan dan Maratun Nafiah \\ Universitas Negeri Jakarta, Indonesia \\ Email: evitaadnan06@gmail.com/nafi_kedu@yahoo.co.id
}

\begin{abstract}
The purpose of this research is to describe the elementary school teacher's strategies in applying remote learning during pandemic Covid - 19 in Kabupaten Bogor, especially in Klapanunggal region, in order to maintain student's mental health. From surveys, interviews, and FGD conducted, this research find that most of the teachers basically have adequate knowledge about the mental health issues and some already consider the issues on the process designing and implementing the strategies. Nevertheless, those strategies can't completely implemented since there are some technical obstacles and the situation of pandemics, include the remote learning policy itself, affect the mental health for both teachers and students. Remote learning reduce the spiritual aspect in learning or called "mattering" such as simple chit - chat and greetings before and during class activities so that leads to student's demotivation on learning.
\end{abstract}

Keywords: learning strategies, remote learning, mental health, elementary school

\section{PENDAHULUAN}

Situasi pandemi Covid - 19 yang telah berlangsung lebih dari satu tahun lamanya berimplikasi pada berbagai sektor kemasyarakatan, tidak terkecuali sektor pendidikan. Pemerintah, melalui Kementerian Pendidikan dan Kebudayaan (Kemdikbud), menerbitkan Surat Edaran Menteri Pendidikan Nomor 4 Tahun 2020 tentang Pelaksanaan Kebijakan Pendidikan Dalam Masa Darurat Penyebaran Coronavirus Disease (Covid-19) menyebutkan bahwa selama pandemi berlangsung proses pembelajaran dari rumah melalui pembelajaran daring/jarak jauh untuk tetap memberikan pengalaman belajar yang bermakna bagi peserta didik.

Sehat mental menurut WHO adalah keadaan sejahtera di mana setiap individu bisa mewujudkan potensi mereka sendiri. Kesehatan mental menentukan bagaimana seseorang dapat berhubungan dengan orang lain, menangani stres dan membuat pilihan. Wahana Visi Indonesia dalam laporannya di Juni 2020 mencatat 47\% anak di Indonesia merasakan kebosanan selama menjalani belajar jarak jauh. Lebih lanjut Satuan Tugas (Satgas) Covid - 19 BNPB menyatakan bahwa 35\% anak di Indonesia khawatir akan ketinggalan pelajaran dan 15\% menyatakan bahwa mereka merindukan teman - teman di sekolah (dalam "47 Persen Anak Indonesia Bosan di Rumah, Akademisi IPB Beri Saran").

Tidak hanya di Indonesia, hal ini juga berlangsung global dimana pandemi Covid - 19 serta penerapan pembelajaran jarak jauh ini berpengaruh, bahkan memperburuk, keadaan kesehatan mental anak di usia sekolah, khususnya sekolah dasar yang disebabkan karena perpaduan antara krisis kesehatan di masyarakat, isolasi sosial yang terjadi, serta resesi ekonomi (Goldberstein, Wei, \& Miller, 2020). Penelitian lain mengatakan bahwa situasi pandemi menyebabkan anak rentan terhadap stress yang termanifestasi pada gangguan tidur, gangguan perilaku, dan lain - lain (Singh dkk, 2020). Oleh sebab itu, tulisan ini akan mengkaji 
bagaimana strategi guru dalam menerapkan pembelajaran jarak jauh yang menunjang kesehatan mental selama masa pandemi Covid - 19 .

\section{METODE}

Kajian ini melibatkan 79 orang guru yang berada di wilayah Kabupaten Bogor, termasuk wilayah Kecamatan Klapanunggal dimana $75 \%$ responden adalah perempuan dan $26 \%$ responden berada dalam rentang usia 26 -35 tahun. Lokasi penelitian ini dipilih karena tidak hanya sebagai daerah peripheral penyangga ibukota namun juga daerah industri dengan skala cukup besar sehingga memiliki karakteristik tersendiri. Sebagai penelitian mixed method, kajian ini menggunakan metode pengumpulan data melalui survei, wawancara, dan FGD dengan metode analisis deskriptif.

\section{HASIL DAN PEMBAHASAN}

\section{Sikap Terhadap Pandemi Covid - 19}

Perubahan yang terjadi selama pandemi Covid -19 memerlukan penyesuaian yang tidak mudah dijalani oleh masyarakat secara umum. Para guru yang terlibat dalam penelitian ini secara psikologis muncul rasa bosan atau jenuh, stress, cemas (anxiety) \& khawatir, serta kelelahan yang disebabkan aktivitas daring. Stress antara lain disebabkan karena tuntutan untuk beradaptasi atas perubahan, tekanan/beban kerja yang lebih berat, ritme kerja yang berubah, dan sebagainya. Tugas yang seakan tidak ada habisnya juga menjadi salah satu penyebab guru mengalami kelelahan mental yang berakhir menjadi stress.

Pembelajaran jarak jauh juga ternyata memunculkan kelelahan tersendiri bagi para guru. Interaksi saat mengajar jarak jauh melalui perangkat digital memberikan rasa yang berbeda jika dibandingkan dengan saat mengajar tatap muka. Brooks dkk (dalam Vibriyanti, 2020) menyatakan bahwa dampak psikologis selama pandemi diantaranya gangguan stres pascatrauma (post-traumatic stress disorder), kebingungan, kegelisahan, frustrasi, ketakutan akan infeksi, insomnia, dan merasa tidak berdaya.

Pada sebagian orang, situasi kurang menyenangkan yang disebabkan oleh pandemi Covid - 19 ini tetap dapat disikapi dengan positif. Beberapa guru menyatakan bahwa di balik situasi pandemi, ada sisi positif yang dapat diambil, seperti menjadi memiliki waktu lebih banyak dengan keluarga, lebih banyak beribadah, lebih memperhatikan kebersihan/sanitasi, hingga lebih memiliki waktu untuk mengembangkan diri dengan menguasai keterampilan baru.

Adaptasi dan berdamai dengan keadaan ini merupakan suatu bentuk penerimaan (acceptance) terhadap situasi yang sedang dihadapi. Perlu digarisbawahi bahwa proses adaptasi tiap orang berbeda - beda ditentukan oleh faktor - faktor seperti : usia, kepribadian, kondisi fisik, proses belajar, dan kondisi lingkungan (Ali dan Asrori dalam Vibriyanti, 2020). Kesuksesan beradaptasi akan melahirkan resiliensi pada diri seseorang. Sedangkan kegagalan beradaptasi akan berdampak pada penurunan kondisi kesehatan mental. Seperti yang dikatakan Mohan (2003) bahwa kesehatan mental adalah kemampuan untuk menghadapi dan menerima realitas kehidupan dengan tekanan dan friksi yang minim. Kemampuan untuk menjadi pribadi yang fleksibel dan adaptif dalam menyikapi kondisi pandemi Covid - 19 juga merupakan salah satu tanda bahwa individu tersebut sehat secara mental.

\section{Pemahaman Terhadap Konsep Kesehatan Mental}

Sebagian besar dari responden $(83,5 \%)$ menyatakan bahwa mereka telah mengetahui isu kesehatan mental jauh sebelum pandemi melanda dan sisanya $(16,5 \%)$ baru mengetahui atau 
mengenal isu ini setelah pandemi. Umumnya, mereka yang menyatakan mengetahui isu kesehatan mental sebelum masa pandemi adalah para guru yang berada dalam rentang usia 26 - 35 tahun. Hal ini tidak mengherankan karena mereka yang berada dalam rentang usia tersebut adalah generasi phi atau generasi milenial yang "melek" teknologi, sangat terbuka terhadap berbagai informasi baru, dan mulai memiliki kepekaan terhadap isu kesehatan mental dibandingkan dengan generasi - generasi sebelumnya.

Para guru pun telah memiliki pemahaman yang cukup baik mengenai kesehatan mental. Misalnya saja dalam memahami hal - hal yang berpengaruh pada kesehatan mental, hampir sebagian besar menyatakan bahwa adanya gangguan pada kesehatan mental atau hal yang memperburuk keadaan kesehatan mental antara lain adanya pengalaman buruk/trauma $(93,7 \%)$, tekanan/stressor $(92,4 \%)$. Namun masih ditemukan pula dalam jumlah yang cukup banyak anggapan bahwa gangguan atau masalah pada kesehatan mental disebabkan oleh kurangnya tingkat keimanan seseorang terhadap Tuhan YME. Hal ini dapat dipahami karena secara awam masih banyak yang menganggap gangguan pada kesehatan mental terjadi karena kurang beribadah, kurang bersyukur, dan sebagainya. Ada pula responden yang menyatakan orang dengan gangguan kesehatan mental sebenarnya adalah mekanisme untuk mencari perhatian $(44,3 \%)$.

\section{Strategi Pembelajaran Jarak Jauh Selama Pandemi Covid - 19}

98\% melaksanakan guru pembelajaran secara jarak jauh (PJJ). Dalam pelaksanaannya, sebagian besar guru melakukan strategi pembelajaran dengan menggabungkan metode video konferensi melalui aplikasi (Zoom Meeting, Google Meet, dan sebagainya) dengan media sosial seperti Whatsapp serta platform lain yang membantu pembelajaran Google Classroom $(63,3 \%)$. Adapun $22,8 \%$ responden guru menyatakan bahwa mereka melakukan pembelajaran daring jarak jauh dengan hanya memanfaatkan Whatsapp dan atau Google Classroom dan 8,9\% menyatakan mereka melakukan blended learning dimana ada jadwal tatap muka dengan jumlah terbatas pada waktu tertentu. Blended learning dilakukan untuk menyiasati kendala pembelajaran jarak jauh, antara lain kuota dan ketersediaan jaringan yang memadai.

Para guru memahami bahwa strategi pembelajaran selama PJJ haruslah semenarik mungkin sehingga mereka menyiapkan video pembelajaran serta melakukan kombinasi aktivitas dengan kuis online. Hal ini diakui awalnya menjadi kendala, namun beberapa guru menyatakan bahwa sekolah memfasilitasi dengan pelatihan pembuatan media pembelajaran.

Menurut para guru, strategi dan metode pembelajaran yang mereka terapkan tersebut dirasa cukup menarik dimana dari 79 orang guru, 41,8\% menyatakan siswa antusias belajar dengan metode yang dilakukan sementara $29 \%$ menyatakan biasa saja, dan 20,3\% menyatakan siswa kurang antusias. Jika dikaji lebih jauh lagi, persentase siswa yang antusiasmenya biasa saja dan kurang antusias sebenarnya lebih besar, yaitu 49,3\%. Hal ini mengindikasikan bahwa dalam pembelajaran jarak jauh walaupun guru telah menyiapkan strategi pembelajaran sedemikian rupa namun kondisi psikologisnya berbeda dengan pembelajaran tatap muka. Siswa cenderung menjadi kurang termotivasi, fokus terpecah, jenuh, dan lelah.

Secara psikologis memang pembelajaran jarak jauh memiliki efek yang berbeda dengan pembelajaran tatap muka. Selain karena tidak adanya interaksi langsung antara guru dengan siswa maupun siswa dengan siswa lain serta kelelahan dan kejenuhan akibat paparan perangkat yang digunakan maupun menumpuknya tugas selama PJJ, ada satu hal yang kerap luput dari perhatian guru adalah mattering. Mattering adalah suatu sikap dalam memandang orang lain sebagai sosok yang penting (Rosenberg \& McCullough dalam Vaillancourt, 2021). Mattering ini adalah hal yang penting di sepanjang rentang perkembangan individu karena terkait dengan 
proses sosial seperti proses afiliasi sosial (social affiliation) dan proses pelekatan (attachment). Perasaan dianggap dan dihargai orang lain ini berhubungan dengan kesehatan mental.

Secara umum, strategi pembelajaran yang dilakukan oleh para guru dalam pembelajaran jarak jauh adalah strategi pembelajaran ekspositori dimana mereka lebih menekankan pada proses penyampaian materi secara verbal dari seorang guru kepada sekelompok siswa, agar siswa dapat menguasai materi secara optimal (Permono, 2014). Strategi ini memang jamak dipilih oleh para pendidik di berbagai level pendidikan. Strategi ini pun cenderung lebih efektif jika mengacu pada waktu belajar yang terbatas dan materi yang harus disampaikan kepada siswa. Evaluasi dilakukan dalam bentuk tanya jawab atau kuis singkat saat kegiatan belajar berlangsung, penugasan, review per subtema atau tema/penilaian harian, serta ujian pada pertengahan dan akhir semester. Terkadang untuk memberikan variasi dalam pembelajaran maka guru akan memberikan tugas berupa pembuatan video dan sepertinya ini merupakan tren di kalangan guru di hampir seluruh tingkat pendidikan.

Pemberian tugas dalam bentuk video tidaklah salah mengingat memang siswa, tidak terkecuali siswa di tingkat pendidikan sekolah dasar, adalah sosok yang sangat dekat dengan media audio visual yang biasa mereka akses antara lain melaui Youtube dan aplikasi lain. Siswa juga saat ini sudah terbiasa menggunakan aplikasi video maker. Sesuatu yang tidak mengherankan mengingat siswa sekolah dasar saat ini merupakan generasi alpha yang memang digital native. Namun guru tidak jarang melupakan bahwasannya membuat video, menurut Taksonomi Bloom yang direvisi oleh Anderson, membuat video berada dalam tahap menciptakan (create) dimana sebelum mencapai tahap tersebut seharusnya siswa telah melalui berbagai tahap, antara lain mengingat (remember), memahami/mengerti (understand), menerapkan (apply), menganalisis (analyze), dan mengevaluasi (evaluate) (Hakim, 2020).

Seperti yang telah disebutkan sebelumnya, dalam menjalankan pembelajaran jarak jauh, sebagian besar guru menyatakan kendala yang paling dirasakan adalah terkait kuota, jaringan yang kurang memadai, dan masalah kepemilikan perangkat pendukung (gadget) bagi siswa. Selain kendala tersebut, beberapa guru mengeluhkan tentang kendala psikologis dalam pelaksanaan pembelajaran jarak jauh antara lain rendahnya motivasi siswa ketika pembelajaran jarak jauh. Komitmen mereka akan kegiatan belajar pun cenderung rendah yang antara lain ditunjukkan pada seringnya siswa terlambat atau bahkan tidak mengumpulkan tugas. Intinya, siswa tidak menunjukkan kepedulian tentang pembelajaran jarak jauh ini. Hal ini tentunya terkait dengan kurangnya attachment antara siswa dan guru selama pembelajaran jarak jauh.

Walaupun pembelajaran berlangsung jarak jauh, kadang guru lupa bahwa siswa tetap perlu "disentuh" sisi psikologisnya. Seperti yang dikatakan oleh Erikson bahwa siswa di usia sekolah dasar berada dalam fase industry vs inferiority sehingga walaupun pembelajaran berlangsung secara daring, guru tetap perlu secara adil memberikan pujian kepada siswa, baik dalam aspek akademis maupun non akademis. Keterbatasan waktu dalam penyampaian materi di pembelajaran jarak jauh seringkali membuat guru cenderung mengabaikan pertimbangan aspek spiritual dalam mempersiapkan strategi pembelajaran padahal hal ini sangat diperlukan.

\section{KESIMPULAN}

Penelitian ini menyimpulkan bahwa pada dasarnya guru telah berusaha menyusun strategi pembelajaran sebaik mungkin untuk diterapkan dalam pembelajaran jarak jauh walaupun memang terbentur kendala - kendala seperti kuota, jaringan, dan keterbatasan kepemilikan 
gawai siswa sehingga akhirnya pembelajaran dirasa kurang maksimal. Hal ini pun terjadi tidak hanya di wilayah penelitian namun juga secara umum di Indonesia yang sarana prasarana untuk pembelajaran daring masih belum sepenuhnya memadai.

Namun yang menjadi perhatian adalah bagaimana dalam menetapkan strategi pembelajaran, guru belum sepenuhnya aware dengan aspek spiritual siswa walaupun memiliki pengetahuan tersebut. Hal ini tidak serta - merta diartikan bahwa guru tidak memikirkan aspek kesehatan mental siswa tetapi adanya "beban" kinerja guru yang lebih ketika pembelajaran jarak jauh antara lain disebabkan karena target materi yang harus dicapai berkejaran dengan waktu belajar yang lebih pendek dibandingkan saat tatap muka.

Durasi waktu belajar yang lebih pendek dengan substansi pembelajaran yang cukup banyak menyebabkan guru kerap mengesampingkan aspek spiritual dalam pembelajaran. Waktu guru untuk menyapa dan bersenda - gurau dengan siswa sebelum dan saat pembelajaran berlangsung atau dikenal dengan konsep "mattering" dirasa berkurang. Hal inilah yang menyebabkan siswa mengalami masalah dalam motivasi dan komitmen dalam belajar selama pembelajaran jarak jauh.

Pada akhirnya, strategi pembelajaran sebaik apapun pada penerapannya tidak akan maksimal ketika guru tidak sehat secara mental. Kesehatan mental guru sangat menentukan suasana pembelajaran yang tentunya akan berpengaruh pada kesehatan mental siswa sebagai peserta didik. Penelitian ini menunjukkan bahwa guru sendiri selama pandemi telah mengalami masalah dalam kesehatan mentalnya walaupun dalam taraf ringan. Oleh sebab itu, guru sebagai salah satu komponen penting dalam pembelajaran terlebih dahulu harus sehat mental agar dapat menciptakan suasana pembelajaran jarak jauh yang juga sehat mental.

\section{DAFTAR PUSTAKA}

Anugrahana, Andri. 2020. Hambatan, Solusi, dan Harapan : Pembelajaran Daring Selama Masa Pandemi Covid - 19 Oleh Guru Sekolah Dasar. Scholaria : Jurnal Pendidikan dan Kebudayaan, Vol 10 (3), September 2020, 282 - 289

Dewi, W. A. F. 2020. Dampak Covid-19 terhadap implementasi pembelajaran daring di Sekolah Dasar. Edukatif: Jurnal Ilmu Pendidikan, 2(1), 55-61.

Golberstein, Ezra, Hefei Wen, Benjamin F. Miller. 2020. Coronavirus Disease 2019 (Covid -

19) and Mental Health for Children and Adolescents. JAMA Pediatrics, April 14. 2020. $\mathrm{E} 1-\mathrm{E} 2$

Haidar dan Salim. 2012. Strategi Pembelajaran (Suatu Pendekatan Bagaimana Kegiatan Belajar Siswa Secara Transformatif). Medan : Perdana

Hakim, Luqman. 2020. Pembelajaran dan Covid - 19 : Momentum Untuk Perubahan, dalam Pedagogik \& Covid-19, Kemungkinan dalam Pendidikan. Jakarta : Taman Pembelajar Rawamangun

Keesing, R., M. 1989. Antropologi Budaya: Suatu Perspektif Kontemporer. Jakarta: Erlangga. Lee, Joyce. 2020. Mental health effects of school closures during COVID-19. Lancet. Child Adolesc. Health, S2352-4642(20)30109-7

Mohan, G. Aruna. 2003. Educational Psychology. New Delhi : Neelkamal Publication

Permono, Hendarti. 2014. Strategi dan Metode Pembelajaran. Prosiding Temu Ilmiah Nasional III Asosiasi Psikologi Pendidikan Indonesia, Pendidikan Yang Memberdayakan, Februari 2014, $136-144$.

Rahmawati, Dwi Nur Umi, Puspita, Ratna Dewi. 2020. Penerapan Manajemen Pembelajaran Di Sekolah Dasar Selama Pandemi. PRODU : Prokurasi Edukasi Jurnal Manajemen Pendidikan Islam, Vol. 2(1), Desember 2020. 50 - 62 
Singh, Shweta, Roy, D. Sinha, K., Parveen, S., Sharma, G., \& Joshi, G. 2020. Impact Of COVID-19 And Lockdown On Mental Health Of Children And Adolescents: A Narrative Review With Recommendations. Psychiatry Research, 293, 113429.

Surat Edaran Menteri Pendidikan Nomor 4 Tahun 2020 tentang Pelaksanaan Kebijakan Pendidikan Dalam Masa Darurat Penyebaran Coronavirus Disease (Covid-19)

Suriansyah, Ahmad dkk. 2014. Strategi Pembelajaran. Jakarta : Rajawali Press

Vaillancourt, Tracy, et.al., 2021. In-Person Versus Online Learning in Relation to Students' Perceptions of Mattering During COVID-19: A Brief Report. Journal of $\begin{array}{lllllll}\text { Psychoeducational Assessment 2021, Vol. } & 0(0), \quad 1 & - & 11\end{array}$ https://doi.org/10.1177\%2F07342829211053668

Vibriyanti, Deshinta. 2020. Kesehatan Mental Masyarakat : Mengelola Kecemasan Di Tengah Pandemi Covid - 19. Jurnal Kependudukan Indonesia Edisi Khusus Demografi dan COVID-19, Juli 2020, $69-74$.

Wahana Visi Indonesia. 2020. Pandemi Covid-19 dan Pengaruhnya Terhadap Anak Indonesia, Sebuah Penilaian Cepat Untuk Inisiasi Pemulihan Awal. Wahana Visi Indonesia, Jakarta.

47 Persen Anak Indonesia Bosan di Rumah, Akademisi IPB Beri Saran“ (https://edukasi.kompas.com/read/2020/11/13/162554571/47-persen-anak-indonesiabosan-di-rumah-akademisi-ipb-beri-saran) 